\title{
Importance of Urine Drug Testing in the Treatment of Chronic Noncancer Pain: Implications of Recent Medicare Policy Changes in Kentucky
}

\author{
John W. Gilbert, MD, G. R. Wheeler, MD, G. E. Mick, DO, B. B. Storey, MD, S. L. Herder, MD, \\ G. B. Richardson, MD, E. Watts, MD, K. Gyarteng-Dakwa, MD, B. S. Marino, MD, \\ C. M. Kenney III, MD, M. Siddiqi, MD, and P. G. Broughton, ARNP
}

From: Spine and Brain Neurosurgical Center, Lexington, $\mathrm{KY}$.

Dr. Gilbert is a neurosurgeon, neuroimagist, pain $\&$ addiction, medicine specialist, Spine and Brain Neurosurgical Center, Lexington, KY. Dr. Wheeler, Dr. Mick, and Dr. Herder are neurosurgeons, Spine and Brain Neurosurgical Center, Lexington,

KY. Dr. Storey is a psychiatrist, Spine and Brain Neurosurgical Center, Lexington, KY. Dr. Richardson

is a physiatrist, Spine and Brain Neurosurgical Center, Lexington, KY. Dr. Watts is a neurologist, Spine and Brain Neurosurgical Center, Lexington, KY. Dr. Gyarteng-Dakwa, Dr. Marino and Dr. Siddiq are anesthesiologists, pain medicine specialists, Spine and Brain Neurosurgical Center, Lexington, KY. Dr. Kenney is a radiologist, neuroradiologist, Spine and Brain Neurosurgical Center, Lexington, KY. Ms. Broughton is a nurse practitioner, Spine and Brain Neurosurgical Center, Lexington, KY.

Address correspondence: John W. Gilbert, MD Spine \& Brain Neurosurgical Center Lexington, $\mathrm{KY}$

E-mail: correspondence@sbncmd.com

Disclaimer: There was no external funding in the preparation of this manuscript. Conflict of interest: None.

Manuscript received: 09/01/2009 Revised manuscript received: 12/10/2009 Accepted for publication: 12/30/2009

Free full manuscript: www.painphysicianjournal.com
Background: Urine drug testing has become a widely used tool in American society for deterring illicit drug use. In the practice of medicine, urine drug testing is commonly used to help diagnose substance misuse, abuse, or addiction.

Objective: This narrative review provides an informed perspective on the importance of urine drug testing in the medical treatment of chronic noncancer pain. The history and current uses of urine drug tests in the United States are reviewed, the prevalence and nature of prescription drug misuse is described as is related to chronic noncancer pain, and implications and considerations for practitioners are presented related to the noncancer pain diagnosis and treatment.

Discussion: Practitioners are confronted with the ethical and legal dilemma of being called to adequately treat chronic pain in a culture with a high prevalence of prescription drug abuse. Yet the symptoms of drug abuse are nonspecific and therefore of limited value to the practitioner in determining patient compliance to drug treatment regimens. In contrast, urine drug testing has a reliable history, both in and out of medicine, as an independent sign of drug misuse. This sign can be used to aid in the diagnosis and treatment of drug misuse and underlying addictions to improve patient outcomes.

Conclusion: Regular urine drug testing should be a part of acute and chronic pain management whether or not the patient has any signs or symptoms of drug misuse.

Key words: chronic noncancer pain, Medicare, Medicaid, urine drug testing, opioids, drug abuse

Pain Physician 2010; 13:167-186

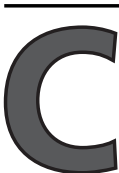
hronic noncancer pain affects more people than any other form of pain (1-3). The Centers for Disease Control and Prevention (CDC) reported that among US adults aged 20 or older in 2002, approximately $42 \%$ reported experiencing pain that lasted longer than one year (4). Similarly, the prevalence of chronic nonmalignant pain within the US veteran general medical population was found to be $48 \%$ (5). Although opioids are used widely to treat chronic pain (6-7), a variety of factors often place these patients at risk for substance abuse, and as such present a complex challenge to the practitioner (721). It is argued that physicians should be encouraged to prescribe opioids because they are indispensable for the treatment of pain and suffering, because uncontrolled pain may have deleterious physical effects, and because persistent pain destroys people's autonomy, dignity, and decision-making capacity 
(7). The Drug Enforcement Administration (DEA) has also taken the position that clinicians should be knowledgeable about using opioids to treat pain, and should not hesitate to prescribe them when opioids are the best clinical choice of treatment (22).

As a result, therapeutic opioid use for noncancer pain is skyrocketing. In pain management settings, it has been reported that as many as $90 \%$ of the patients were prescribed opioids for chronic pain (15). Opioids increased from 50.7 million grams of medication dispensed in 1997 to 115.3 million grams of medication dispensed in 2006, an overall increase of $127 \%$ (7).

Along with the increase in therapeutic opioid use has come an increase in opioid abuse and addiction (7-21). Nonmedical use of prescription pain relievers is second only to marijuana in US illicit drug use (23). Opioid abuse accounted for $5 \%$ of 2007 admissions to substance abuse treatment services (24). Also of note, Americans consume $80 \%$ of the global opioid supply (7), and an estimated 5.2 million persons self-reported having used prescription pain relievers in the month preceding a 2007 drug use survey (25).

At the state level, Kentucky, as well as Tennessee, rank in the top fifth nationwide for nonmedical use of prescription drugs, tranquilizers, and the nonmedical use of pain relievers (primarily narcotics) (23).

In comparison, Indiana ranks highest for nonmedical use of pain relievers for all age groups except those aged 12 to 17 years (26); West Virginia ranks within the top 10 (27), whereas Ohio remains below the national average (28). Prescription drugs, usually polypharmacy from multiple physicians, have been involved in the majority of unintentional drug overdoses, the number of which has nearly doubled in Kentucky over the past 5 years (29). Moreover, Kentucky is home to higher than average rates of tobacco use, government-insured individuals, and unemployment. All are factors linked with higher than average drug abuse rates (30).

This environment has motivated Kentucky to take aggressive corrective actions. For example, Kentucky Senate Bill 63 passed in 2004 requiring pseudoephedrine to be obtained by requesting it from a pharmacist; This, plus aggressive public awareness, helped reduce the production of methamphetamine (31). Kentucky has limited access to mail-order pharmacies, increased law enforcement programs, and added drug courts to its legal system (3234). The success of the Kentucky All Schedule Prescription Electronic Reporting (KASPER) led to the enactment of the National All Schedule Prescription Electronic Reporting (NASPER) $(35,36)$.
Based on the evidence of a statewide problem with substance abuse, practitioners also have an important, but difficult, role in screening patients undergoing opioid treatment for pain. Clinical signs of drug abuse are often difficult to diagnose. Over $90 \%$ of family physicians reportedly miss the classic signs of substance abuse (37). Research suggests that self-reporting of compliance alone is an insufficient screening tool, and that safety monitoring would be enhanced by routine urine toxicology screening. This study also indicated that the presence of behavioral issues did not predict urine toxicology results, thus monitoring should not be based solely on aberrant behaviors (38). Urine drug testing (UDT) provides the practitioner with a valuable tool to keep accurate records, to identify use of unprescribed substances, and to determine appropriate intake of prescribed substances $(8,13)$.

UDT is not only a crucial element in monitoring patient compliance in opioid therapy, but it may also save lives, as there has been a rapid increase in fatal opioid overdoses $(21,39)$. From 1996 to 2006, the number of fatal poisonings involving opioid analgesics more than tripled, from 4,000 to 13,800 deaths (39). In 2006, opioid analgesics were involved in almost $40 \%$ of all poisoning deaths, up from about 20\% in 1999 (39).

Kentucky, however, has allegedly been confronted with a major setback in the control of prescription drug abuse and the concomitant protection of public health and safety. Specifically, effective for dates of service on or after July 1, 2009, Medicare local carrier determinations for Medicare part B providers in Connecticut, Indiana, Kentucky, and New York were revised to no longer recognize qualitative drug screens as medically reasonable and necessary unless the patient is suspected of drug overdose and one or more of the following conditions: unexplained altered mental state in the absence of clinically defined toxic syndrome; severe or unexplained cardiovascular instability; unexplained metabolic or respiratory acidosis in the absence of clinically defined toxic syndrome; seizures with undetermined history; monitoring patient's compliance during active treatment for substance abuse or dependence; monitoring of a chronic pain patient with iatrogenic opioid dependence and some other illicit drug use suspected (40). In short, this policy change eliminates the use of routine or random UDT both in patients with acute or chronic cancer or noncancer pain and in patients being treated for drug misuse, abuse, or addiction, because at current Medicare fee schedules most patients are unable to afford these laboratory panels out of pocket. A standard point-of-care immunoassay costs up to $\$ 220$ per test. 
In response to this barrier to using UDTs in chronic pain management, this paper was developed to provide an informed and timely perspective on the importance of UDT in the medical treatment of chronic pain. We review the history and current uses of UDT in the United States, describe the prevalence and nature of prescription drug abuse as it relates to chronic pain, and present implications and considerations for practitioners in the role of UDTs in chronic pain diagnosis and treatment.

\section{History and Current Uses of Urine Drug Testing}

Although over 120 million drug tests are performed annually in the United States (41), drug testing has a relatively young history. A synopsis of that history and current uses of drug testing in government, private industry, and medicine follows.

\section{Government and Industry}

\section{The Military}

UDT has its roots in military drug testing programs, which evolved from the high rate of drug use in the 1970 s among returning Vietnam veterans, as well as the US Navy finding of a drug use rate approaching 50\% (42). In response, the military established drug testing laboratories and a urine testing program in 1971 that included all personnel reporting for active duty (43). After the institution of drug testing, the rate of positive screens plummeted. For example, the rate of positive screens reported by the Department of the Navy declined from approximately $50 \%$ to approximately $1 \%$ (42).

\section{The Workplace}

The success of military programs led to the initiation of the Federal Workplace Drug Testing program $(42,44)$. In 1986, Executive Order 12564 prohibited federal employees from using illegal drugs, mandated that all federal agencies develop plans to make their workplaces drug-free, and instituted voluntary drug testing programs (45). Patterned after military drug testing programs, these civilian programs were intended to deter workers from the use of illicit drugs and to identify drug users and refer them to treatment. They were not designed to identify every drug user or abolish drug use in the workplace (42). Physicians play a crucial role as medical review officers (MROs) in workplace drug testing programs, especially in cases when positive test results have acceptable medical explanations; such results can then be appropriately reported to the employer as negative by a certified MRO (46). Workplace drug testing programs primarily entail random testing, as a deterrent rather than a method to detect drug use. These programs differ from the periodic, scheduled tests performed in branches of the military (e.g., US Coast Guard) (42).

A landmark study on the cost effectiveness of workplace testing was conducted in the late 1980s by the US Postal Service in Boston, which agreed to conduct drug testing without acting on the results. Of note, compared with employees with negative pre-employment test results, employees with positive pre-employment test results had higher rates of accidents, injuries, job turnover, and other adverse employment outcomes. A cost benefit analysis of drug testing showed a cost savings to the Postal Service of $\$ 162$ per job applicant annually $(47,48)$.

Drug testing in the private sector has since expanded beyond federal program requirements to include pre-employment and post-accident urine drug testing. Collectively, the workplace now accounts for about 40 million drug tests annually (49). Whether mandated by the federal program or in the private sector, a well designed and implemented drug testing program is a valuable tool for reducing drug use in the workplace (50). Urine drug tests have become the most common method for testing because of the ease of sampling and low analytical costs. One survey showed that over $90 \%$ of companies with more than 5,000 employees have some type of drug testing program in place (51). Programs have been shown to reduce the rate of positive drug test results and be of significant economic benefit to the employer $(51,52)$. The drug testing index of Quest Diagnostics showed a decline in the rate of positive drug tests from $18 \%$ in 1987 to $4.4 \%$ by 2002 (42). Moeller and colleagues (52) found a favorable benefitto-cost ratio of UDT in the workplace of 26 to one.

\section{The Criminal Justice System}

Of drug tests performed in the United States, the largest number, exceeding 40 million annually, are performed under the auspices of the criminal justice system (i.e., drug courts, corrections, probation, parole and drug treatment programs) (41), in many cases after people have developed addiction disorders. Therapeutic jurisprudence (i.e., drug courts) has been particularly effective in combating recurrent drug use or relapse, with urine drug screens being an essential tool in that process. Indeed, drug courts can serve as a primer 
for physicians. Individuals in drug courts start out with at least 2 random drug tests per week during the first phase of drug testing (53). Similarly, student drug testing programs almost always include random and reasonable suspicion testing and many programs include periodic testing such as at the beginning of an athletic season with follow-up tests weekly, biweekly, or monthly (42). Perhaps if large-scale screening programs were universally in place (e.g., through physicians or schools) to guide people into early treatment, drug use might rarely advance past early stages such as experimental (e.g., youthful), recreational (e.g., with friends), or circumstantial (e.g., coping with life stresses).

\section{Opiate Addiction and Its Treatment}

No discussion of UDT is complete without reviewing the history and current status of opiate addiction treatment. In 1933, in response to prohibition and public outcry, the federal government opened a US Public Health Service Hospital in Lexington, Kentucky, aimed at inpatient treatment of opiate addiction (54). Subsequent to the failure of inpatient opiate addiction treatment, 12-step programs emerged. The first predecessor meeting to Narcotics Anonymous was held in Lexington, Kentucky, in 1947 (55).

Opiate addiction is a chronic complex disease involving psychological, physiological, genetic, behavioral, and environmental factors and at best can be managed but not cured. Cure in this sense is usually defined as progressively longer periods between relapses. Today, common approaches to treatment include nonprofessional-based programs such as 12-step programs along with psychosocial behavioral health consultations and UDTs, as well as outpatient federally regulated methadone treatment programs and office-based treatment programs using buprenorphine/naloxone.

Federal regulations mandate that patients receive no more than $30 \mathrm{mg}$ of methadone at initial dosing since individuals suffering from addiction are known to exaggerate their drug intake. In the past, methadone treatment programs often started patients on higher doses with resultant bad outcomes (e.g., death from respiratory depression). Federal methadone guidelines suggest a minimal standard for urinalysis to include analysis for opiates, methadone, amphetamines, cocaine, and barbiturates, as well as any drug recognized by the program as prone to abuse in the local area. Additional standards and regulations may exceed these requirements as developed by individual states. Current regulations also require an admission UDT and a minimum of 8 UDTs in the first year of treatment in a methadone program. Of note, methadone clinics typically see individuals on a daily basis and patients usually are not permitted to take medication home and advance to monthly intervals between office visits until nearly 2 years into treatment (56).

Polydrug use and abuse among opiate addicts is the rule. Three or more drug combinations are involved in over $40 \%$ to $50 \%$ of emergency department (ED) visits (57). Wasserman and colleagues (58) compared results from twice weekly testing versus less frequent testing in 166 patients at 4 methadone maintenance treatment programs. The data suggested that standard UDT practices in methadone maintenance treatment programs may underestimate the prevalence of opioid and cocaine use. More frequent testing, even for timelimited periods, should more accurately depict drug use prevalence and help direct interventions. Chutuape and colleagues (59) examined the effects of UDT frequency on treatment outcomes and contingent methadone take-home programs. Their results suggest abstinence can be sustained with UDT conducted as infrequently as once a month. Ojaniemi and colleagues (60) showed that polydrug findings were common $(77 \%)$ in driving under the influence cases and they noted an 18-fold increase in driving under the influence among drug cases. Ehrman and colleagues (61) showed that a single pretreatment urine test was a powerful predictor of cocaine use over a subsequent 4-week period. Epstein and colleagues (62) showed that in 252 heroin and cocaine abusing outpatients on methadone maintenance, the frequency of opiate and cocaine dependence diagnosis decreased in the active intervention groups utilizing a novel contingency that reinforced abstinence from either drug while doubly reinforcing simultaneous abstinence from both. The main outcome measures were a percentage of urine specimens negative for heroin, cocaine, and both simultaneously.

\section{Primary Care Medicine}

Chronic pain affects an estimated 50 million people in this country, yet most US medical schools do not provide comprehensive education in pain treatment (63). For this reason, primary care physicians are frequently left at a disadvantage in dealing with the complex issues associated with pain treatment. Over $90 \%$ of family physicians reportedly miss the classic signs of substance abuse (37), and more than half of patients report that their family physician did not address substance abuse. Nevertheless, despite these shortcomings, the majority 
of chronic pain patients in this country are managed by primary care physicians. For these reasons, the use of routine urine toxicology by primary care physicians is recommended (64), and is thought to improve patient function and outcomes by identifying opioid misuse, overdose, and addiction; to deter and identify illicit drug use; to confirm appropriate opioid or controlledmedication use; and to reduce patient and physician liability. Yet, underutilization of UDTs by primary care physicians is common, and many physicians lack an adequate understanding of the complexities of UDTs and factors that can affect test results (65).

Bhamb and colleagues (66) noted that urine toxicology can be easily incorporated into the routine care of chronic pain patients with minimal patient resistance as long as all patients receive uniform treatment. They also noted in their survey of 248 primary care physicians that the majority were comfortable in prescribing narcotics or opioids to patients with terminal cancer; however, they were less comfortable prescribing opioids or narcotics to patients with low back pain or those with a concurrent history of drug or alcohol abuse. Only about $6.9 \%$ of primary care physicians obtained a UDT before prescribing opioids (66). Likewise, Tellioglu (67) suggests urine testing is a practical, inexpensive, and valuable tool in general medical practice for patient guidance and treatment planning and asserts that UDTs are underutilized in the clinical setting. Similarly, of 80,000 admissions from 1990 through 1994 to a tertiary care oncology center, Passik and colleagues (68) found UDTs were used infrequently; they recommended that the appropriate use and documentation of UDTs should be a focus of staff education and quality improvement efforts. There is a need for effective, straightforward guidelines for addressing issues faced by primary care physicians. Options that have been suggested include utilizing treatment agreements and conducting routine urine toxicology screening on all patients before starting narcotic therapy (66). The use of UDTs is supported by research conducted in San Francisco that identified $50 \%$ more illicit opioid users by conducting urine toxicology screens twice a week versus less frequent testing (58). In a recent article in JAMA, Kuehn (69) suggests routine, periodic, or regular UDT in pain patients who are asymptomatic for drug use and/or at low risk for drug abuse.

\section{Pain Medicine}

Opioid misuse occurs frequently in chronic pain patients and structured monitoring for opioid misuse can potentially ensure the appropriate use of opioids in chronic pain management and mitigate adverse public health effects of diversion (70). Urine drug tests provide objective information regarding licit and illicit drug use patterns in chronic pain patients (71). Katz and colleagues (38) noted that requiring a report of behavioral issues and urine toxicology tests for patients prescribed chronic opioids creates a more comprehensive monitoring system than either requirement alone, and noted that pain management centers showed a significant prevalence of noncompliance with regard to consumption of non-prescribed medication and illicit substance use; they recommended routine urine toxicology in the clinical management of all patients receiving opioid therapy. Jung and Reidenberg (72) found that physicians are unable to detect patients misusing medications up to $90 \%$ of the time through observation and self-reporting only. Furthermore, the researchers noted that in the current legal environment surrounding the prescribing of opioids, accepting patient reports of pain at face value can have significant negative legal consequences for the physician. Fishbain and colleagues (73) noted that a significant percentage of chronic pain patients appear to provide incorrect information on current illicit drug use. While physicians must make every reasonable effort to confirm the diagnosis needed for opioids, allowance must be made for the fact that even conscientious doctors can be deceived a significant portion of the time $(72,74)$.

Heit (75) described a uniform protocol of urine testing for every patient receiving opioids for pain and at a minimum does an initial test and 2 tests thereafter in the first year; he notes that UDT is perhaps one of the most important tools for the pain clinician. In addition, he notes a number of other tools are helpful. They include prescription monitoring systems, pill counts, short intervals dispensing methods, tighter controls, limits on prescribing, a single dispensing pharmacist, and documentation. However, experts point out that even these limits would not completely eliminate drug diversion or its use, since no perfect system exists $(7,12,14,76)$.

UDT and integration of laboratory diagnostics into routine clinical practice is essential and has been shown to significantly reduce illicit drug use in this population $(14,20,77)$. UDT, although still underutilized, has become an essential feature in safe pain management. Analysis of urine is an integral component in the care of those on chronic opioid therapy to diagnose relapse and drug misuse as early as possible so as to offer treatment for that disease and advocate for the patient with third-party interests $(78,79)$. Patient-centered UDTs are 
objective diagnostic tests for the treatment of the subjective complaint of pain, just as observed-urine donation or chain-of-custody testing (i.e., forensic UDT, MRO testing) is an objective test used to measure compliance with pain treatment plans, the presence of specific prescribed medications, and the absence of non-prescribed medications (79). Urine samples from 470 chronic pain patients who had UDT in a pain management program at an urban teaching hospital showed a $45 \%$ prevalence of abnormal findings from urine drug screens analyzed and confirmed using gas chromatography mass spectrometry (GC-MS). Common patient descriptors such as number, type, or dose of prescribed opioids were poor predictors of abnormal results (80). Physicians at the Pain Trials Center at Brigham and Women's Hospital in Boston concluded that it is appropriate to conduct routine urine toxicology testing in all patients with chronic pain treated with opioids (81). The need has been emphasized for scrupulous monitoring of adherence to appropriate dosage and maintenance of opioid prescription by a single physician when using opioids in headache treatment (82).

\section{Prescription Drug Abuse}

Treatment of chronic pain is essential to overall health. In fact, chronic pain over time has been shown to atrophy the brain (83). Thus, undertreating pain can be deemed unethical for purposes of complying with state medical licensure board guidelines and can give rise to significant civil liability. Numerous well-publicized cases for the under treatment of pain illustrate that physicians can be found liable. Given the increased number of patients suffering from pain, the number of claims of under treatment can be expected to increase (84-86).

Chronic severe pain has been shown to be prevalent among patients in substance abuse treatment centers, especially methadone maintenance treatment programs (87). In a pain survey administered to patients attending an outpatient drug and alcohol treatment program, only $13 \%$ of patients with chronic severe pain were currently receiving pain treatment (88). However, the treatment of chronic pain is often complicated by a myriad of patient-specific, societal, and regulatory factors that can complicate the physician's decision to prescribe opioids (12).

\section{Prevalence of Prescription Drug Abuse}

The use of prescription pain relievers without a physician's prescription accounts for the second most common form of illicit drug use in the United States
(89). Misused opioids are obtained directly from a physician $19 \%$ of the time and/or provided by a friend or relative $56 \%$ of the time (90). Pain patients reported significantly more health problems, psychiatric disturbances, prescription and nonprescription medication misuse, and a greater belief that they were undertreated than patients treated for opiate addiction (91).

The number of Americans treated for abuse of painkillers in society increased by a factor of 5 since 1997. This statistic is based on the 2007 Treatment Episode Data Set of admissions to state-licensed or certified treatment facilities (92). From 1992 to 2002, while the US population increased $13 \%$, the number of prescriptions filled for controlled substances rose $154 \%$. In that same period new abuse of prescription opioids among 12- to-17-year-olds increased $542 \%$, more than 4 times the rate increase seen among adults (93). From 2002 to 2007 , the nonmedical use of prescription pain relievers increased among young adults aged 18 to 25 (from 4.1 to $4.6 \%)$, among adults aged 50 to 54 (3.4 to $5.7 \%)$, and among adults aged 55 to 59 (from 1.9 to $4.1 \%$ ) (94). In 2002, 9.9\% of all drug-related ED mentions involved opioids (93). The number of deaths involving prescription opioid analgesics increased from approximately 2,900 in 1999 to approximately 7,500 in 2004, a rise of $160 \%$ in just 5 years (95). Because misuse of prescription opioids has led to an epidemic of opioid-related deaths, greater use of opioid agreements and UDTs are urged $(96,97)$.

\section{Kentucky}

Kentucky residents are ranked among the nation's top abusers of prescription drugs for non-medical purposes, pain relievers for non-medical use, and tranquilizers for non-medical use (29). In Kentucky, unintentional fatal drug overdoses have doubled over the past 5 years and overdoses are the number 2 cause of accidental deaths after car crashes. Prescription drugs remain the chief cause of this increase in deaths with one in 5 teens abusing prescription pain medicine, one in 5 abusing prescription stimulants and tranquilizers, and one in 10 abusing cough medicine. There was a $212 \%$ increase in 12- to 17 -year-olds abusing controlled substances, a $155 \%$ increase in prescriptions written for controlled substances, and an $81 \%$ increase in adults abusing controlled substances from 1992 through 2003 (93). Seventy percent of tenth grade students in some regions of the state feel that drug use is a problem in their school; up to $50 \%$ of tenth graders believe that drug dealing is a problem in their school (98). From 
2002 to 2005, treatment admissions to publicly funded programs among individuals aged 12 to 20 years increased $84 \%$ (99). Ecstasy (3,4-methylenedioxymethamphetamine [MDMA]), ketamine, GHB (gamma-hydroxybutyric acid), and LSD (lysergic acid diethylamide) remain readily available in Kentucky and are primarily used by teenagers and young adults in towns or cities that have universities or colleges (82). The abuse and diversion of prescription drugs remains one of the largest, if not the largest, drug problems in southeastern Kentucky. Marijuana, methamphetamine, cocaine, and diverted pharmaceuticals have remained primary drug threats in Kentucky, and Mexican black tar heroin use has risen in the Louisville area along with misuse of other drugs (100).

\section{Risk Factors for Prescription Drug Abuse}

\section{Smoking}

Smoking is an addictive disorder that may be an indicator of predisposition for drug abuse. Patients who smoked have 5 times the incidence of illicit drug use compared with nonsmokers, and a $40 \%$ incidence of monthly binge drinking (101). Stable everyday smoking was positively correlated with an increased probability of a positive urine drug test for illicit drug use (102). Seventy-one percent of recent illicit drug users have smoked cigarettes at least once in the past month; the odds of a smoker being an illicit drug user are much greater than those of the general population (103). Moreover, the negative effects of nicotine on overall health are substantial, with over 400,000 deaths per year in the United States attributed to nicotine addiction (104). Pain patients have been shown to have higher rates of smoking than non-pain patients (105), and pain rates have been found to be higher among current and heavy smokers compared with people who have never smoked (106). Indeed, smoking is associated with degenerative disc disease and low back pain (107), as well as higher failure rates in surgical interventions such as spinal fusions ( $8 \%$ for nonsmokers versus $40 \%$ in smokers) (108). The association between pain and smoking is of special concern in regions like Kentucky where rates of tobacco use exceed the national average.

\section{Alcohol Consumption}

Alcohol use can be an indicator of predisposition for drug abuse. In 2007, alcohol use in the US population was found to be pervasive; $51.1 \%$ of Americans aged 12 and older reported being current drinkers of alcohol (at least one drink in the last 30 days) (89). Of 17 million heavy drinkers ( 5 or more drinks at the same occasion on each of 5 or more days in the past 30 days) aged 12 or older, $31.3 \%$ reported being current illicit drug users (89). Patients who use illicit drugs or who engage in alcohol abuse or misuse are at very high risk for prescription drug abuse. Numerous studies of chronic pain patients suggest that the prevalence of substance misuse may approach one-fourth of chronic pain patients receiving opioids $(70,109-111)$.

In 2007, of 22.3 million Americans meeting criteria for substance abuse of drugs or alcohol, only 3.9 million received treatment (89). Patients with these disorders rarely admit to current or past substance abuse and often withhold medical information or alter records $(72,74)$. Because they often deny any signs or symptoms; answer negative to narcotic abuse, screening, and history questions; and/or are sophisticated in hiding any signs from clinicians, UDT is imperative in this population. Frequently, the abnormal urine drug test will be the first abnormal sign in this population. The effects of alcohol or benzodiazepines or marijuana or barbiturates, along with depressant effects of opiates, significantly increase the risk of respiratory depression and death. The significance of alcohol use in pain management is even greater in view of anticipated increases in the misuse or abuse of alcohol and illicit drugs by baby boomers, since this demographic group has higher rates of substance use compared with earlier generations of Americans $(112,113)$.

\section{Chronic Pain}

Chronic pain patients are at higher than average risk for drug abuse and are indistinguishable from the drug abuse population. Self-reporting of drug use (prescribed or otherwise) has been found to be unreliable in chronic pain patients (81). Various studies confirm problem drug behavior in chronic pain patients, with approximately $14 \%$ to $34 \%$ of pain patients having been found to abuse prescription medications $(114,115)$. In an interventional pain setting, Manchikanti and colleagues (115) found that $24 \%$ of patients significantly abused opioids; abuse was frequent in about $50 \%$ of these patients. For example, problem drug behavior was reported in $50 \%$ of chronic headache patients in a 3-year period (116). A host study of approximately 33,000 patients who were prescribed oxycodone found that $12 \%$ had no oxycodone in their urine, $16 \%$ had no opioids in their urine, and $35 \%$ were not within the ex- 
pected ranges for urine concentration-dose curves; $40 \%$ of the diverted oxycodone had been recycled to other patients (117). All patients at a pain management clinic ( $60 \%$ on oxycodone, $22 \%$ on methadone, and $20 \%$ on morphine) were subjected to GC-MS confirmed urine drug testing. A high rate $(45 \%)$ of abnormal findings on urine toxicology tests were noted, with $20 \%$ having illicit substances in their urine, $14.5 \%$ having additional drugs, and $10 \%$ missing the prescribed opioid. In addition, benzodiazepines were found in $22 \%$, marijuana in $15 \%$, and cocaine in $7 \%$ (118).

Chronic noncancer pain patients seen in our Kentucky practice are asked to try a slow-stepped approach to their overall plan of care and alternative and adjunctive treatments. The most conservative approaches are treatments such as physical therapy, chiropractic therapy, osteopathic therapy, occupational and functional and vocational rehabilitation, non-opioid pain management, and psychological intervention. If a patient has failed to see results from conservative treatments, then we offer interventional techniques such as epidural blocks for radiculopathy, facet blocks for spinal facet pain, occipital nerve blocks, rhizotomies, and other interventional techniques. If patients have failed conservative treatments and interventional techniques, we also provide open neurosurgical procedures such as discectomies, laminectomies, fusions, implant intrathecal pumps for back pain, as well as implant intraspinal epidural electrodes and pulse generators to treat radiculopathy and other disorders, as indicated. It is only after these treatments have proved ineffective that opioid drug therapy is recommended.

\section{Psychiatric comorbidity}

The high prevalence of mental health disorders and substance use/misuse disorders in the chronic pain population can potentially reduce the efficacy of a standard chronic pain treatment program $(6,119)$. An increased rate of drug misuse problems has been found in patients with mental disorders such as anxiety, depression, and antisocial personality disorder (120). Overall, patients seeking treatment at specialty mental health or substance abuse treatment facilities have been found to be 2 to 4 times more likely to have co-occurring mental and substance abuse disorders compared with persons not seeking treatment (121). Psychiatric comorbidities in pain patients were found to occur in over $55 \%$ of 228 patients who demonstrated aberrant drug-taking behaviors (122), with depression being the most prevalent mental illness among substance abusers
$(120,123)$. Fifty percent of chronic pain patients have been found to contemplate suicide (124). Depression is the single biggest factor in suicide, with more than $70 \%$ of suicides having been found to occur in patients who had been depressed (125). Substance abuse is common in individuals who attempt or complete suicide (126128). Kentucky averages 36 suicide attempts per 50,000 population and a rate of 7 suicide deaths per 50,000 people (129).

Patient mental health status can further complicate treatment and must be considered especially when the patient is transitioning between health care providers or health care settings (130). For example, patients with mental illness may need a family member to dispense, monitor, and control their psychiatric and pain medications that may be prescribed during the 30-day discharge period. It is probably best to offer noncompliant patients nonopioid treatment options before a patient self-releases from a practice to possibly seek opioids elsewhere. A patient with a lethal triad (125) of psychosis, suicide plan, and a recent past suicide attempt requires immediate referral to a behavioral health specialist.

\section{Other Factors}

Factors such as age, low socioeconomic status, unemployment, and comorbid conditions may also be risk factors for prescription drug abuse. Factors such as age, low socioeconomic status, unemployment, and comorbid conditions may also be risk factors for prescription drug abuse. In 2007, adults aged 18 to 26 years were found to have a substance abuse rate $(19.7 \%)$ approximately 3.4 times higher than that of adults aged 26 or older (5.8\%) (23). Unemployed adults were found to have a substance abuse rate $(18.3 \%)$ that was over twice that of those who were employed full time (8.4\%) (23). In Kentucky, Medicare and Medicaid patients were shown to have an increased rate of abuse of illicit drugs, with Medicaid patients having a $43.6 \%$ rate of substance use disorders (131).

Selected outcomes of interventional techniques and surgeries may be adversely affected by drug addiction disorder (132-134). However, controversy exists on some of these aspects (135-173). There is a known higher risk of implant failure in patients with mental illness, alcoholism, drug abuse, or lifestyle factors that can complicate their surgical procedure (132). Patients should be narcotics-free before placement of spinal cord stimulator leads, and patients should have no untreated substance abuse when considering implanta- 
tion of an intrathecal medication pump $(133,134)$.

\section{The Battle Against Prescription Drug Abuse}

\section{Prescription Monitoring Plans}

KASPER is a tracking system reporting all narcotic prescriptions for an individual, tells which doctors prescribed them and what pharmacy dispensed them $(35,36,174)$. Of note, however, methadone treatment programs in emergency departments and hospitals do not report to KASPER $(35,36,175)$. KASPER served as a model for the National All Schedule Prescription Electronic Reporting System (NASPER), which began in 2005 (35-36). A federal grant is available to help states set up their own electronic tracking systems for narcotic prescriptions using federal rules of operation. This program, however, does not absolve physicians of their responsibility to monitor and prescribe responsibly (123).

\section{Urine Drug Testing}

UDT is recommended by the American Society of Interventional Pain Physicians, the Federation of State Medical Boards, the American Pain Society, the American Academy of Pain Medicine, the American Society of Addiction Medicine, the Department of Veterans Affairs, and other organizations. The Federation of State Medical Boards and Kentucky Board of Medical Licensure guidelines all call for appropriate evaluation and treatment plans, medical records, and the appropriate use of monitoring such as UDT $(176,177)$. A national standard was suggested by Federation of State Medical Board guidelines and was endorsed by the DEA in 1998. The failure to monitor or address abuse/addiction issues and inadequate record keeping have been crucial in DEA cases against physicians.

A variety of federal guidelines are designed to address substance abuse problems. A Substance Abuse and Mental Health Services Administration (SAMHSA) consensus panel recommends that programs incorporate federal and state regulatory requirements and local practice treatment needs into written policies and procedures for drug testing and integrate these policies and procedures into treatment planning and practices (178). The SAMHSA and federal regulations require 8 drug tests per year for patients in maintenance treatment (179). In the opinion of the consensus panel, this is a minimal requirement and more testing should be performed earlier in treatment than later (178).

The American Pain Society opioid guidelines suggest frequent UDTs (i.e., weekly, biweekly, or monthly) although some pain specialists note that the UDT be done during every office visit (180). While such guidelines are useful to clinicians, individual treatment plans, of course, must be based on patient history, diagnosis, and circumstances.

The US Food and Drug Administration (FDA) mandates Risk Evaluation and Mitigation Strategies (REMS) that entail more physician training for 24 controlledrelease opioids and methadone. For example, Wooden notes that checking urine for signs of abuse and ordering smaller numbers of high-dose pills are good practices (181).

The Utah Department of Health has recommended drug testing before initiating long-term opioid treatment for all patients. When a test is positive, they recommend that practitioners consider referral to substance abuse counseling and a pain management specialist and that the patient be more carefully monitored (182). The state of Louisiana requires pain management clinics to be licensed and for patients to undergo UDTs on admission and at least 4 times annually during treatment (183).

In short, as a simple and noninvasive approach to biological sample screening, urine is the specimen of choice for pain management services (13). UDTs are routine practice in chronic pain management settings to potentially improve medical-legal compliance and reduce regulatory scrutiny by improving documentation and preventing inappropriate patient dismissal or treatment bias. UDTs may help support specialist referrals and identify the use of illicit substances throughout treatment and provide objective data to assist in making appropriate decisions regarding medications. UDT provides the physician with an objective test that documents prescription use, misuse, abuse, and illicit drug use; identifies patient noncompliance with selfreporting; clarifies behavioral observations; and provides support for patient relapse prevention (13). Urine drug tests may also improve treatment adherence by providing the doctor with objective documentation of prescription drug adherence and a correlation of medication to pain matrix and behavioral symptoms.

UDTs may allow the identification and quantification of potential violations of the patient treatment agreement. They can also identify the use of medications or other sources that may complicate the treatment plan as well as provide objective evidence and knowledge to adjust pharmacotherapy. UDTs can also help identify patients who divert medications and assist in the identification of misuse of prescription medica- 
tions and potential addiction or relapse issues, and further reduce the risk of therapeutic failure by detecting patients who are non-adherent to the treatment plan. Enhancing appropriate prescribing may minimize the risk of patient doctor shopping and noncompliance (184).

Note: The term urine drug screening is not used in medicine because it implies a generic screening without a physician order for all patients, for all types of visits, without physician review (e.g., reviews by non-medical personnel as conducted at health fair screens), without integration into a treatment plan for any and all drugs; it is impossible to prove the presence or absence of all drugs (185).

In short, UDTs are essential for the diagnosis and treatment of pain and associated drug misuse diagnoses as well as the diagnosis of noncompliance or compliance, all of which serve to guide the patient along appropriate treatment paths, thus improving the functioning of the patient. Accurate and timely diagnosis of drug misuse is extremely important since the vast majority of drug misuse involves recreational, experimental, or circumstantial use. The signs or symptoms of these forms of use are difficult to detect; hence, physicians rely on UDTs of the patient to detect recent use. In comparison, fewer patients abuse, and even a far lower percentage meet the requirements for addiction. Patients must have significant problems (e.g., divorce, driving under the influence, loss of employment) in the last 12 months to meet the requirements for diagnosis of active abuse or addiction since tolerance, withdrawal, and taking medications for periods longer than initially intended are common in normal non-abusing, non-addicted pain patients.

\section{Formulating Clinical Diagnoses and Treatment Plans}

The treating physician must integrate patient symptoms (subjective) and signs (objective) to formulate and modify clinical diagnoses and treatment plans $(78,186,187)$. This process can be especially complex in patients when standard treatment options involve the prescription of opioids, as is the case of patients who suffer from chronic pain. Subjective, self-reporting of pain level and drug use are crucial symptoms in the development of diagnoses and treatment plans. Unfortunately, the reliability of these subjective data is low in this patient population. For this reason, the physician must rely more heavily on objective signs or measures of disease, such as those obtained through physical ex- amination and analytical tests such as UDTs, magnetic resonance imaging, pain patient profile $(P-3 \circledast$, Pearson, Eagan, MN, USA), and KASPER reports of controlled substance use. In general, such signs are more reliable than symptoms derived through patient history. Certain tests have more sensitivity and specificity than other tests depending on the complaint being evaluated. Moreover, clinical diagnoses and treatment plans must both be revisited regularly to accurately reflect up-to-date signs and symptoms. These data should be viewed through the lens of known risk factors and behaviors that are strongly linked to drug misuse (e.g., unemployment, government insurance, suicidal thought or behavior, alcohol use, age, isolation, change in school/work performance, muscle aches, numbness, anxiety, depression, controlled substance use, other symptoms/signs). Physicians should be cognizant of new research through continuing medical education and stay informed concerning local drug use trends.

The frequency of opioid use before presenting to an interventional pain management setting has been shown to be more than $90 \%$ (15). Thus, patients presenting to pain care clinics who have been previously treated in primary care settings where drug testing is under utilized may not be adequately controlled or stabilized; may be under- or over-medicated; or may not have drug misuse or noncompliance diagnosed by the time they are referred to the pain or addiction specialist.

In Kentucky, the vast majority of primary care physicians refer patients to pain specialty practices after failure to control acute pain. Moreover, in our experience the vast majority (over $80 \%$ ) of referring physicians want only to see the patient back for routine medical care. They want the pain specialist to assume responsibility for all opioid patients, more complex patients, problem patients, or patients who have had increasing problems despite very high doses of opioids. Thus, the specialist is frequently confronted with challenging scenarios for medication management.

\section{Diagnosing Drug Misuse and Addiction}

Treating pain can often be difficult in patients who have a comorbid substance abuse disorder $(152,188$ 191). When treating a new patient referred for the complaint of pain, the practitioner must look for the underlying International Classification of Diseases (ICD) diagnosis (e.g., ruptured disc, stenosis) and simultaneously diagnose the patient's level of compliance with the referring physician's treatment plan. In established 
patients, the practitioner must continually assess for changes in the underlying ICD diagnosis, while simultaneously assessing for drug misuse, abuse, or addiction. The American Society of Interventional Pain Physicians (ASIPP) guidelines recommend adherence monitoring by screening for opioid abuse, UDT, and periodic monitoring of treatment goals and patient compliance (8).

\section{Diagnostic Criteria}

In general, drug and alcohol disorders are diagnosed based on the specific criteria (i.e., DSM-IV criteria, ICD-9 criteria, definitions from the American Society of Addiction Medicine, American Pain Society and American Academy of Pain Medicine, Certified Medical Review Officer Training, and other sources). Most pain and addiction physicians consider parts of the DSMIV psychiatric definitions not helpful since typically patients can develop tolerance and withdrawal from drugs such as steroids, antidepressants, and even opioids without having any criteria for abuse or addiction or other disorder.

Addiction to drugs or alcohol is the most severe substance-abuse diagnosis. Most professionals feel the patient must have repeated negative consequences yet continue to use a certain drug or alcohol to qualify for the diagnosis of addiction. For example, part of the DSMIV criteria for active diagnosis of drug abuse involves one or more of the following in a 12-month period: a) recurrent drug use resulting in failure to fulfill major role obligations at work or school; b) recurrent drug use in situations that are physically hazardous such as driving under the influence; c) recurrent drug-related legal problems such as arrest and disorderly conduct; or d) continued drug use despite persistent or recurrent social or interpersonal problems. On the other hand, drug addiction involves 3 or more of the above-mentioned problems occurring in the past 12 -month period and is fortunately more rare than drug abuse. Fortunately, the vast majority of patients do not fit the criteria for abuse or addiction, but rather fall in the category of drug misuse or a combination of diagnoses such as recreational, circumstantial, or experimental use.

\section{Urine Drug Testing}

UDT alone usually does not diagnose drug addiction, physical dependence, or impairment; however, it can aid in the diagnosis, treatment, and improvement of these conditions (192). UDT offers the standard of care to improve the accuracy of diagnoses, the early detection of drug misuse or abuse, the deterrence of unwanted diagnoses (e.g., noncompliance with medical treatment ICD = V15.81), and thus improves treatments, function, and outcomes. A consistent policy and protocol for UDT that applies to all patients is essential in a medical practice (8). UDT should also be considered for: all new patients or when modifying treatment; for any patient resistant to evaluation; for any patient requesting a specific drug; for any patient displaying aberrant behavior; for any patient with psychiatric comorbidities; for any established patient with unexpected results on initial UDT; for any patient with problems in urine collection, including sample dilution or temperature outside the normal range $\left(90-100^{\circ} \mathrm{F}\right)$; family or workplace reports of impaired behavior; high drug tolerance; for patients with problems of adherence; reports of early or lost prescriptions or noncompliance; pharmacy calls of concern; for those with continued high-risk behavior; and other indications $(78,185)$.

\section{Clinical Considerations}

Most patients do not exhibit any easily detectable signs or symptoms when drug use is occasional (i.e., recreational, circumstantial, or experimental) or when the patient abuses prescription medications privately. Conversely, stable, compliant patients who are prescribed opioids usually do not have any signs or symptoms, yet the physician still needs to confirm compliance with their treatment contract. Keep in mind that patients who report chronic pain frequently misrepresent their pain level or substance use to their physicians. One study of a pain practice showed that over $50 \%$ of patients had non-prescribed narcotics or alcohol or illicit drugs in their urine, and approximately $45 \%$ had a negative urine study for the drugs being prescribed for their pain (68). Therefore, categorically believing patients when they say they hurt and prescribing any treatment (surgery/injections/opioids/non-opioids) before doing any drug testing is a clinical mistake, since undiagnosed drug use disorders (and associated diseases such as hepatitis) and noncompliance can complicate even a non-opioid drug regimen.

Most patients after history and physical and review of abnormal UDT results can be diagnosed with noncompliance with their treatment plan (i.e., ICD V15.81), involving recreational, experimental, or circumstantial drug use. Typically, fewer patients qualify for a diagnosis of abuse disorder and fewer yet qualify for a diagnosis of addiction. These diagnoses commonly require the integration of data that are both subjective (patient history) and objective (e.g., UDT, KASPER report). Pre- 
scription monitoring systems such as KASPER are limited in that they track only prescribed medications, whereas UDTs reliably provide a way to objectively assess illicit or illegal drug use (e.g., cocaine, THC, methamphetamine, phencyclidine [PCP]). In cases, for example, when a UDT is positive for THC and the patient denies use in the past 60 days and is taking a medication such as a proton pump inhibitor, the practitioner may then want to proceed with GC-MS confirmatory testing. Fortunately, the detection time utilizing the most common urine drug immunoassays is up to 72 hours or even longer for cocaine. For drugs such as marijuana, diazepam, and PCP the detection window may be far longer than a week.

\section{Treatment Plans}

In our practice we use a universal precautions approach to the treatment of chronic pain to achieve improved treatment, function, and outcomes. The universal precautions include a written contract between the patient and health care professionals providing care and independent compliance measures in the form of regular UDTS. Regular UDT is the most important universal precaution in treating chronic noncancer pain followed by prescription-monitoring programs such as KASPER $(35,36,175,193,194)$. UDT and adherence monitoring including controlled-substance agreements or various periodic or regular or routine measures of compliance have been associated with a $50 \%$ reduction in opioid use (195).

\section{Opioid Treatment Regimens}

Opioids remain the most effective tool the practitioner has for controlling chronic intractable pain (4). Practitioners practicing pain or addiction medicine should begin patients at low doses; physicians should go slow when titrating opioid medications and err on the conservative side when changing treatment programs, since there is incomplete cross-tolerance between different types of opioids. There is an odds ratio of 4960:1 that a presenting patient will already have tried an illicit substance compared with the risk that the physician will initiate the disease of opiate addiction (196).

\section{How Often Should UDT Be Performed?}

Arguably, physicians have the highest ethical or professional obligation to detect patients who have underlying drug misuse disorders, drug abuse disorders, addiction disorders, or other problems and to steer them to the proper form of medical treatment. Yet $90 \%$ of family physicians have been reported to miss the classic signs of substance abuse such as abnormal urine drug tests (37).

The federal government mandates a minimum 8 or more UDTs (i.e., twice a week for the first 30 days and at least monthly thereafter) in the first year of treatment in methadone (schedule II opioid) treatment programs for the chronic disease of opiate addiction even though individuals in methadone treatment programs are seen daily by treatment specialists for the first year (56). In contrast, stable pain patients on schedule II opioids are usually only seen by pain treatment specialists at one to 3-month intervals. Yet opiate addiction and chronic pain are both chronic diseases and share many similarities in that they are frequently not cured and can only be managed, not unlike diabetes or hypertension. Moreover, urine collection can be observed or monitored in an opiate addiction treatment program unlike a private physician's office that uses UDTs primarily for chronic noncancer pain and/or drug abuse addiction treatment. Unlike methadone treatment programs where patients have known addiction disorders, the pain physician is confronted with ongoing treatment of patients with unknown addiction-related tendencies. Compared with methadone treatment programs, pain specialists have relatively infrequent face-to-face interaction with their patients. Because of the relative infrequency that stable patients being treated for chronic pain are seen by their prescribing physician, practitioners in the fields of chronic noncancer pain and/or outpatient abuse and addiction treatment who utilize 12-step programs and behavioral health and other modalities may be well advised to institute more UDTs more frequently than the number federally mandated for methadone treatment centers.

In the treatment of chronic pain the physician is dealing with patients who are being considered for controlled substances or who have been prescribed controlled substances, and who continue to engage in safety-sensitive functions such as driving, operating machinery, and raising children. Practitioners may want to consider implementing regular UDTs to aid in the diagnosis and treatment of drug misuse, abuse, or addiction so that patients can receive the proper form of treatment. That treatment may include behavioral health and/or addiction physician evaluation as further enhancements to patient care, as opposed to purely random programs designed to deter use, like government and workplace drug testing programs. For example, after an infraction by a covered employee, a substance abuse professional must abide by federal regulations 
that the employee take at least 6 follow-up urine drug tests (UDTs) within the first 12 months after resuming safety-sensitive functions $(42,197)$. In comparison, a practitioner who primarily practices pain management may want to perform initial testing and random testing thereafter to diagnose patient compliance. Federal regulations mandate that persons who are presumably drug-free must have 6 follow-up UDTs before resuming safety-sensitive functions. It follows that physicians should consider the safety implications of patients taking opioids or other controlled substances for the treatment of pain, especially if they drive or operate machinery and consider monitoring patients more closely with frequent UDTs.

Moreover, if the practitioner also practices addiction medicine and has a psychiatrist, behavioral health professionals, or addiction physicians available, he or she may want to consider a routine testing protocol to detect potential drug misuse, abuse, or addiction to aid in getting such patients into treatment.

UDT for patients with drug misuse, abuse, or addiction should be performed as many times as necessary to document adherence to a mutually agreed upon treatment plan; those with only pain management without comorbidities who are being stabilized may have tests as often as needed, or as infrequently as 3 times a year, if stable $(78,135)$. UDT in the clinical practice can validate the patient's history, document the patient's diagnosis, allow treatment assessment, improve treatment planning, improve clinical management of the patient, improve public safety, improve the patient's advocacy, and help prevent relapse. Marcus (198) at the University of Pittsburgh Medical Center recommends routine urine toxicology testing to ensure opioid compliance by providing prescriptions only when due and with regular UDTs.

The UDT protocol should be tailored to the clinic's location and type of practice. For example, Kozma (199), who practices practical pain management, reports seeing his stable patients every 4 weeks with UDTs at each visit (13 UDTs per year) and notes that routine UDT is more readily accepted by patients when it is implemented as an integral part of the drug treatment program and makes UDTs part of his opioid agreement. Patients at his clinic understand the concept "no urine, no prescription, no exceptions." Patients with a substance abuse history and/or comorbidities or dual diagnoses or confirmed noncompliance will need continuous multidisciplinary care, including psychology and/or psychiatry and addictionology, in addition to more frequent visits and increased monitoring. (Costs related to UDTS are discussed below.)

\section{Clinical Considerations}

The patient who may meet the criteria for drug misuse frequently presents with no signs or symptoms, and denies any history consistent with a diagnosis. Patients who meet the difficult-to-detect criteria for addiction can be skilled at circumventing detection (e.g., frequently have no readily available visible injection sites or needle tracks or other discernible findings). Physical examinations are usually only positive if individuals present in an acute intoxicated state. However, when drug use is experimental or circumstantial, urine drug tests can be helpful. For example, marijuana can test as positive in urine for as long as 2 months after its last use.

Again, practitioners need to be cognizant of the medical literature and the increased rates of problems in patients with disorders such as bipolar, borderline personality disorder, schizophrenia, psychosis, anxiety, depression, or family history of drug or alcohol problems. Studies show that $90 \%$ of patients treated in pain management settings are on opioids and/or additional controlled substances $(7,8,15)$. Thus, given the fact that depression is the number one cause of suicide, pain physicians must constantly be concerned about the types and number of medications available to any one patient and must also understand that opioids over time may, in fact, induce depression. In treating these complex patients, physicians must consider long-term trends measured by objective assessments such as pain patient psychological assessment, behavioral health assessment, UDT, and other factors to formulate longterm treatment plans and ensure patient compliance.

\section{Cost-Benefit Considerations in Urine Drug Testing}

Cost-benefit analyses performed through the Federal Workplace Drug Testing Program, methadone clinics, and other areas, have likewise shown a definite cost benefit to UDTs in this complex population. It has been estimated that each UDT costs Medicare up to $\$ 220$ per physician office payment and up to an additional $\$ 250$ for GC-MS confirmatory testing when it is sent out to a commercial laboratory. The practitioner must balance cost-benefit factors in relation to history, physical diagnosis, and treatment plans. One cost advantage in point-of-care testing is that follow-up office visits to review test results are not needed, unlike when the ser- 
vices of commercial laboratories are used. In addition to this cost advantage, it is well known that the patients who go off site for UDT have greater opportunity to adulterate their urine test compared with patients who receive point-of-care testing (200).

Also it must be borne in mind that most hospitals and national laboratories that perform UDT by physician request routinely perform UDT panels that include 10 to 12 tests, whereas smaller, private laboratories typically offer limited UDT panels (i.e., 7 or 8 tests). In either case, even if the referring physician has not ordered a GC-MS confirmatory test, some laboratories will proceed with confirmatory testing, based on their own internal policies. Unnecessary GC-MS confirmatory testing obviously constitutes an additional cost to the patient. In most cases, point-of-care testing integrated with knowledgeable questioning of patients by the treating physician or staff can minimize the use of confirmatory GC-MS testing. Unfortunately, most hospital laboratories actually outsource the GC-MS confirmatory testing. In our experience, the turnaround time for these tests is typically 2 weeks, during which time the physician and patient are left in limbo. A prudent physician would want to see the patient back to review the results and decide on continuation of opioids. Kozma (199), a pain physician, says that he sees all patients treated with controlled substances (including stable patients) every 4 weeks and requires point-of-care testing. Based on this clinical information, a practitioner may want to consider seeing patients more frequently than every 4 weeks if he is going to be outsourcing his urine drug testing. This increased frequency would obviously have a negative economic effect on the patient and/or the payer. Individual practice protocols may differ from the frequency suggested in ASIPP guidelines. Physicians must tailor testing protocol to patient population, geographic location, state board of medical licensure requirements, and other factors.

\section{Conclusion}

Practitioners are confronted with the ethical and legal dilemmas of being called to adequately treat chronic pain in a culture with a high prevalence of prescription drug abuse. Unfortunately, the symptoms of drug abuse are nonspecific and therefore of limited value to the practitioner in determining patient compliance to drug treatment regimens. In contrast, UDT has a reliable history, both in and out of medicine, as an independent sign of drug misuse that can be used to aid in the diagnosis and treatment of underlying addictions. Accurate and up-to-date histories, together with the objective findings of UDTs, allow practitioners to formulate accurate, up-to-date clinical diagnoses and treatment plans that can be used to bring patients into early treatment and improve patient outcomes.

Controlling health care costs by eliminating unnecessary testing is a goal we can all respect and support (201-208). However, far from unnecessary, UDTs are an essential tool in opioid compliance monitoring in the complex, chronic noncancer pain patient population. We must be careful not to limit the resources and ability of physicians to responsibly prescribe opioid analgesics when medically indicated. Certainly point-of-care UDTs offer a cost control solution that has been shown 1) to provide more reliable information to clinicians compared with off-site testing and 2 ) to greatly reduce the need for confirmatory testing if accompanied by patient interviews. A closer examination of the use of UDTs in the treatment of chronic noncancer pain is warranted to determine policies and safeguards to ensure that payments for UDTs meet Medicare requirements.

\section{Acknowledgments}

We would like to thank the editorial board of Pain Physician for review and criticism in improving the manuscript.

\section{References}

1. Bedard M. Fact sheet on chronic nonmalignant pain 1997. www.druglibrary. org/schaffer/asap/factsheet.html. Accessed April 19, 2009.

2. Manchikanti L. Singh V, Datta S, Cohen SP, Hirsch JA. Comprehensive review of epidemiology, scope, and impact of spinal pain. Pain Physician 2009; 12:E35E70.
3. Manchikanti L, Boswell MV, Singh V, Benyamin RM, Fellows B, Abdi S, Buenaventura RM, Conn A, Datta S, Derby R, Falco FJE, Erhart S, Diwan S, Hayek SM, Helm S, Parr AT, Schultz DM, Smith HS, Wolfer LR, Hirsch JA. Comprehensive evidence-based guidelines for interventional techniques in the management of chronic spinal pain. Pain Physi- cian 2009: 12:699-802.

4. Centers for Disease Control and Prevention National Center for Health Statistics. Health, United States, 2006 with chartbook on trends in the health of Americans. Hyattsville, MD, 2006.

5. Clark J. Chronic pain prevalence and analgesic prescribing in a general medical population. J Pain Symp Management 
2002; 23:131-137.

6. Burgess F. Highlights from pain, opioids, and addiction: An urgent problem for doctors and patients. Medscape Neurology and Neurosurgery 2007. www.medscape.com/viewarticle/555145_print. Accessed April 13, 2009.

7. Manchikanti L, Singh A. Therapeutic opioids: A ten-year perspective on the complexities and complications of the escalating use, abuse, and nonmedical use of opioids. Pain Physician 2008; 11: S63-S88.

8. Trescot A, Helm S, Hansen H, Benyamin R, Glaser S, Adlaka R, Patel S, Manchikanti L. Opioids in the management of chronic non-cancer pain An update of American Society of Interventional Pain Physicians' (ASIPP) Guidelines. Pain Physician 2008; 11: S5-S62.

9. Benyamin R, Trescot AM, Datta S, Buenaventura R, Adlaka R, Sehgal N, Glaser SE, Vallejo R. Opioid complications and side effects. Pain Physician 2008; 11:S105-S120.

10. Smith HS. Peripherally-acting opioids. Pain Physician 2008; 11:S121-S132.

11. Trescot AM, Datta S, Lee M, Hansen H. Opioid pharmacology. Pain Physician 2008; 11:S133-S153.

12. Manchikanti L, Atluri S, Trescot AM, Giordano J. Monitoring opioid adherence in chronic pain patients: Tools, techniques, and utility. Pain Physician 2008; 11:S155-S180.

13. Trescot AM, Glaser SE, Hansen $\mathrm{H}, \mathrm{Be}$ nyamin R, Patel S, Manchikanti L. Effectiveness of opioids in the treatment of chronic non-cancer pain. Pain Physician 2008; 11:S181-S200.

14. Manchikanti L, Manchukonda R, Pampati V, Damron K, Brandon D, Cash K, McManus C. Does random urine drug testing reduce illicit drug use in chronic pain patients receiving opioids? Pain Physician 2006; 9:123-129.

15. Manchikanti L, Cash KA, Damron KS, Manchukonda R, Pampati V, McManus CD. Controlled substance abuse and illicit drug use in chronic pain patients: An evaluation of multiple variables. Pain Physician 2006; 9:215-226.

16. Manchikanti L, Giordano J, Boswell MV, Fellows B, Manchukonda R, Pampati V. Psychological factors as predictors of opioid abuse and illicit drug use in chronic pain patients. J Opioid Manage 2007; 3:89-100.
17. Manchikanti L, Manchukonda R, Damron KS, Brandon D, McManus CD, Cash $\mathrm{KA}$. Does adherence monitoring reduce controlled substance abuse in chronic pain patients? Pain Physician 2006; 9:57-60.

18. Manchikanti L, Fellows B, Damron KS Pampati V, McManus CD. Prevalence of illicit drug use among individuals with chronic pain in the Commonwealth of Kentucky: An evaluation of patterns and trends. J Ky Med Assoc 2005; 103:5562.

19. Manchikanti L, Pampati V, Damron KS, Beyer CD, Barnhill RC, Fellows B. Prevalence of prescription drug abuse and dependency in patients with chronic pain in western Kentucky. J KY Med Assoc 2003; 101:511-517.

20. Manchikanti L, Damron KS, McManus $C D$, Barnhill RC. Patterns of illicit drug use and opioid abuse in patients with chronic pain at initial evaluation: A prospective, observational study. Pain Physician 2004; 7:431-437.

21. Manchikanti KN, Manchikanti L, Damron KS, Pampati V, Fellows B. Increasing deaths from opioid analgesics in the United States: An evaluation in an interventional pain management practice. $J$ Opioid Manage 2008; 4:271-283.

22. Practitioner's Manual: An informational outline of the controlled substance act of 1970. Drug Enforcement Administration 2006.

23. NSDUH Report: Trends in Nonmedical Use of Prescription Pain Relievers: 2002 to 2007. Substance Abuse and Mental Health Services Administration Office of Applied Studies. February 5, 2009.

24. Treatment Episode Data Set (TEDS): 1997-2007. National Admission to Substance Abuse Treatment Services. Substance Abuse and Mental Health Services Administration Office of Applied Studies 2009(DASIS Series S-47).

25. 2007 National Survey on Drug Use and Health. Rockville, MD: U.S. Substance Abuse and Mental Health Services Ad ministration; 2008.

26. Substance Abuse and Mental Health Services Office of Applied Studies. States in Brief: Indiana 2008. www. samhsa.gov/statesinbrief/2009/INDIANA_508.pdf. Accessed November 9, 2009.

27. Substance Abuse and Mental Health Services Office of Applied Studies. States in Brief: West Virginia 2008. www.samhsa.gov/statesinbrief/2009/
WEST_VIRGINIA_508.pdf. Accessed November 9, 2009.

28. Substance Abuse and Mental Health Services Office of Applied Studies. States in Brief: Ohio. 2008. www.samhsa.gov/statesinbrief/2009/OHIO_508. pdf. Accessed November 9, 2009.

29. Kentucky Office of Drug Control Policy. Prescription drug abuse facts. 2009. http://odcp.ky.gov/NR/ rdonlyres/01D7C27D-4E92-49399D6F-843E5D8A26E4/o/MicrosoftWordPrescriptionDrugAbuseFacts.pdf. Accessed July 29, 2009.

30. Kasier Family Foundation. State health facts. 2009. http://statehealthfacts. org. Accessed August 28, 2009.

31. Kentucky Justice \& Public Safety Cabinet. Governor Ernie Fletcher holds ceremonial bill signing for anti-meth \& internet pharmacy legislation. 2005. http://justice.ky.gov/pressreleases/ methsigning.htm. Accessed August 29, 2009.

32. Kentucky Revised Statute. 315.0351 Out-of-state pharmacy - Permit - Requests for information - Records - Tollfree telephone service - Pharmacist on duty - Requirements for out-of-state pharmacy doing business on the Internet. 2007. www.lrc.ky.gov/krs/315oo/0351.pdf. Accessed July 29, 2009.

33. Kentucky Revised Statute. 533.010. Criteria for utilizing chapter - Alternative sentences - monitoring by private agency - work release 2009. www.lrc. ky.gov/krs/533-00/010.pdf.

34. Kentucky Revised Statute. 533.250 Pretrial diversion program in each judicial circuit - Elements - Fee. 2009. www.lrc. ky.gov/krs/533-00/250.pdf. Accessed July 29, 2009.

35. Manchikanti L, Whitfield E, Pallone F. Evolution of the National All Schedules Prescription Electronic Reporting Act (NASPER): A public law for balancing treatment of pain and drug abuse and diversion. Pain Physician 2005; 8:335347.

36. Wang J, Christo PJ. The influence of prescription monitoring programs on chronic pain management. Pain Physician 2009; 12:507-515.

37. Goldfarb B. Primary care physicians often miss signs of drug abuse in pain patients. Pain Med News 2005; 3(6). www.painmedicinenews.com/index.asp?section $\mathrm{i} d=82 \& \mathrm{show}=\mathrm{dept} \&$ is sue $i d=120 \&$ article_id $=4287$. Accessed 
March 14, 2010.38. Katz N, Sherburne S, Beach M, Rose R, Vielguth J, Bradley J, Fanciullo G. Behavioral monitoring and urine toxicology testing in patients receiving long-term opioid therapy. Anesth Analg 2003; 97:1097-1102.

39. Warner M, Chen L, Makuc D. Increase in fatal poisonings involving opioid analgesics in the United States, 1999-2006. NCHS Data Brief 2009(22). www.cdc. gov/nchs/data/databriefs/db22.htm

40. Centers for Medicare and Medicaid Services. Qualitative drug screening L28145. 2009. www.ngsmedicare.com/ NGSMedicare/Icd/DL28145_f_Icd.htm.

41. Reynolds L. Historical aspects of drugsof-abuse testing in the United States. In: Wong R, Tse H, (eds). Forensic Science and Medicine: Drugs of Abuse: Body Fluid Testing. Humana Press, Totowa, NJ, 2006.

42. Swotinsky R, Smith D. The Medical Review Officer's Manual. 3rd ed. OEM Press, Beverly Farms, MA, 2006.

43. TRICARE Management Activity. Military drug program historical timeline. 2008. www.tricare. $\mathrm{mil} / \mathrm{tma} / \mathrm{DDRP} / \mathrm{docu}$ ments/72208/DoD\%20Drug\%20Polic y\%20History.pdf. Accessed August 10, 2009.

44. MacDonald D, DuPont R, Ferguson J. The role of the medical review officer. In: Graham A, Schultz T, Smith MM, Ries R, Wilford B, (eds). Principles of Addiction Medicine. American Society of Addiction Medicine, Chevy Chase, MD, 2003: 944.

45. Reagan R. Drug-free federal workplace: 51 FR 32889, 3 CFR, 1986 Comp., p. 224.

46. Clark H. The role of physicians as medical review officers in workplace drug testing programs: In pursuit of the last nanogram. West / Med 1990; 152:514524.

47. Zwerling C, Ryan J, Orav EJ. The efficacy of preemployment drug screening for marijuana and cocaine in predicting employment outcome. JAMA 1990; 264:2639-2643.

48. Zwerling C, Ryan J, Orav EJ. Costs and benefits of preemployment drug screening. JAMA 1992; 267:91-93.

49. Judge W. Workplace drug testing's mixed success. Behavioral healthcare. 2007 www.behavioral.net/ME2/dirmod.asp?sid $=\& n m=\&$ type $=$ Publishin g\&mod=Publications\%3A\%3AArticle\& $\mathrm{mid}=64 \mathrm{D} 490 \mathrm{AC} 6 \mathrm{~A} 7 \mathrm{D} 4 \mathrm{FE} 1 \mathrm{AEB} 453627 \mathrm{~F}$ $1 \mathrm{~A}_{4} \mathrm{~A}_{32} \&$ id $={ }_{0} \mathrm{C}_{9} \mathrm{~F}_{5} 6 \mathrm{~F} 8 \mathrm{~A}_{9} \mathrm{~A}_{34} \mathrm{FA}_{5} \mathrm{AoD} 9$
9CA94EFoB6D5\&tier=4. Accessed August 28, 2009.

50. Gerson B, Subramaniam S. Drug testing as part of the war on drugs. Clin Lab Med 1998; 18:781-803.

51. Peat M. Financial viability of screening for drugs of abuse. Clin Chem 1995; 41:805-808.

52. Moeller K, Lee K, Kissack J. Urine drug screening: Practical guide for clinicians. Mayo Clin Proc 2008; 83:66-76.

53. Lessenger J, Roper G. Drug courts: A primer for the family physician. I $A m$ Board Fam Pract 2002; 15:298-303.

54. Laudet A. The impact of Alcoholics Anonymous on other substance abuse related Twelve Step programs. Recent Dev Alcohol 2008; 18:71-89.

55. Narcotics Anonymous. 2009. http:// wapedia.mobi/en/Narcotics_Anonymous. Accessed August 29, 2009.

56. U.S. Food and Drug Administration. Conditions for the use of narcotic drugs. 21 CFR 291505. 2000. http://frwebgate.access.gpo.gov/cgi-bin/getcfr.cgi $?$ TITLE $=21 \&$ PART $=291 \&$ SECTIO $\mathrm{N}=505 \& Y E A R=2000 \&$ TYPE $=$ TEXT. AC cessed June 11, 2009.

57. U.S. Department of Health and Human Services. Emergency Department Trends from the Drug Abuse Warning Network, Preliminary Estimates January-June 2002. Rockville, MD. SAMHSA Office of Applied Studies, 2002.

58. Wasserman D, Korcha R, Havassy B, Hall S. Detection of illicit opioid and cocaine use in methadone maintenance treatment. Am J Drug Alcohol Abuse 1999; 25:561-571.

59. Chutuape M, Silverman K, Stitzer M. Effects of urine testing frequency on outcome in a methadone take-home contingency program. Drug and Alcohol Depend 2001; 62:69-76.

6o. Ojaniemi K, Lintoen T, Impinen A, Lillsunde $P$, Ostamo A. Trends in driving under the influence of drugs: A register-based study of DUID suspects during 1977-2007. Accid Anal Prev 2009; 41:191-196.

61. Ehrman R, Robbins S, Cornish J. Results of a baseline urine test predict levels of cocaine use during treatment. Drug and Alcohol Depend 2001; 62:1-7.

62. Epstein D, Schmittner J, Umbricht A, Schroeder J, Moolchan E, Preston K. Promoting abstinence from cocaine and heroin with a methadone dose increase and a novel contingency. Drug and Alcohol Depend 2009; 101:92-100.
63. Lukachko A. Pain education lacking in medical school curricula. Primary Care Quarterly 2009; 5(9).

64. Kuznar W. Understanding of opioids key to chronic pain treatment. Int Med World Rept 2007(June). www. hcplive.com/primary-care/publications/internal-medicine-world-report/2007/2007-06/2007-06_31. Accessed March 14, 2010.

65. Reisfield G, Salazar E, Bertholf R. Rational use and interpretation of urine drug testing in chronic opioid therapy. Ann Clin Lab Sci 2007; 37:301-14.

66. Bhamb B, Brown D, Hariharan J, Anderson J, Balousek S, Fleming M. Survey of select practice behaviors by primary care physicians on the use of opioids for chronic pain. Curr Med Res Opin 2006; 22:1859-1865.

67. Tellioglu T. The use of urine drug testing to monitor patients receiving chronic opioid therapy for persistent pain conditions. Med Health R I 2008; 91:279280.

68. Passik S, Schreider J, Kirsch K, Portenoy $R$. A chart review of the ordering and documentation or urine toxicology screens in a cancer center: Do they influence pain management? J Pain Symptom Manage 2000; 19:40-44.

69. Kuehn BM. Efforts aim to curb opioid deaths, injuries. JAMA 2009; 301:12135 .

70. Ives T, Chelminski P, Hammett-Stabler C, Malone R, Perhac J, Potisek N, Shilliday B, DeWait D, Pignone M. Predictors of opioid misuse in patients with chronic pain: A prospective cohort study. BMC Health Serv Res 2006; 6:46.

71. Cone E, Caplan Y, Black D, Robert T, Moser F. UDT of chronic pain patients: Licit and illicit drug patterns. J Anal Toxicol 2008; 32:530-543.

72. Jung B, Reidenberg M. Physicians being deceived. Pain Med 2007; 8:433-7.

73. Fishbain D, Cutler R, Rosomoff H, Rosomoff R. Validity of self-reported drug use in chronic pain patients. Clin J Pain 1999; 15:184-191.

74. Passik S, Kirsch K. Commentary on Jung and Reidenberg's "Physicians Being Deceived": Aberrant drug-tak ing behaviors: What pain physicians can know (or should know). Pain Med 2007; 8:442-4.

75. Garcia L 2008 - 8th ICPCD highlights review 3: Role of urine drug testing in monitoring pain and addiction therapy: Is it worth it? Faculty presenter Howard 
Heit. 2008. www.emergingsolutionsinpain.com/index. php?option=com_con tent\&task=view\&id=398\&ltemid $=105$ . Accessed August 10, 2009.

76. Beresford L, Dhingra LK. Tools for pain and opioid abuse risk assessment. Medscape 2009. http://cme.medscape.com/viewarticle/585622. Accessed May 8, 2009.

77. Fornari F, Siwicki D, Bauer G. Urine testing and monitoring in pain management. Practical Pain Management July 2006.

78. Heit HA, Gourlay D. Urine drug testing in pain medicine. J Pain Symp Manage. ment 2004; 27:260-7.

79. Kleber HD, Heit HA, Nicholson B. Opioid Risk Management: Dispelling the Myths and Integrating Clinical Strategies to Protect Your Practice. Purdue University, West Lafayette, IN, 2009.

8o. Michna E, Jamison R, Pham L, Ross E, Janfaza D, Nedeljkovic S, Narang S, Palombi D, Wasan A. Urine toxicology screening among chronic pain patients on opioid therapy: Frequency and predictability of abnormal findings. Clin J Pain 2007; 23:173-9.

81. Katz N, Fanciullo G. Role of urine toxicology testing in the management of chronic opioid therapy. Clin J Pain 2002; 18:S76-S82.

82. Ziegler D. Opioids in headache treatment: Is there a role? Neurol Clin 1997; 15:199-207.

83. Tennant F. Brain atrophy with chronic pain. Practical Pain Management 2009; 9.

84. Estate of Henry James $v$ Hillhaven Corp, 89 (North Carolina Sup. Ct. Div 1991).

85. Bergman v Chin, H205732 (Cal. Super. Ct. Alameda County 2001).

86. Tomlinson v Bayberry Care Center, C 02-00120 (Cal. Super. Ct. Contra Costa County 2002).

87. Rosenblum A, Joseph H, Fong C, Kipnis S, Cleland C, Portenoy R. Prevalence and characteristics of chronic pain among chemically dependent patients in methadone maintenance and residential treatment facilities. JAMA 2003; 289:2370-8.

88. Barry DT, Beitel M, Cutter C), Garnet B, Joshi D, Schottenfeld RS, Rounsaville BJ. Allopathic, complementary, and alternative medical treatment utilization for pain among methadone-maintained patients. Am J Addict 2009; 18:379385 .
89. Office of Applied Studies. Results from the National Survey on Drug Use and Health: National findings (DHHS Publication No. SMA 08-4343, NSDUH Series H-34). 2008. www.drugabuse.gov/ Infofacts/PainMed.html. Accessed August 28, 2009.

90. National survey of drug use and health. Rockville, MD: U.S. Department of Health and Human Services, Substance Abuse and Mental Health Services Administration; 2007.

91. Jamison R, Kauffman J, Katz N. Characteristics of methadone maintenance patients with chronic pain. J Pain Symptom Manage 2000; 19:53-62.

92. New report cites surge in painkiller abuse admissions. Primary care quarterly 2009; 9. www.pcquarterly.com/index.asp?section id $=171 \&$ show $=$ dept \& is sue $i d=514 \&$ article_id $=13082$. Accessed March 14, 2010.

93. Bollinger L, Bush C, Califano J, Chenault K, Curtis J, Dimon J, Dolan P, Flsher M, Ganzi V, Kelmenson L-A, Keough D, Kessler D, Malloy E, Pacheco M, Plumeri J, Redstone S, Rosenwald E, Schulhof M, Sullivan L, Sweeney J, Wiener M. Under the counter: The diversion and abuse of controlled prescription drugs in the U.S. The National Center on Addiction and Substance Abuse at Columbia University; 2005.

94. The NSDUH Report: Trends in Nonmedical Use of Prescription Pain Relievers: 2002 to 2007. Rockville, MD: Substance Abuse and Mental Health Services Administration OoAS; 2009.

95. Paulozzi L. Trends in unintentional drug poisoning deaths. Committee on Energy \& Commerce, Subcommittee on Oversight \& Investigations, United States House of Representatives: CDC Congressional Testimony; October 24, 2007.

96. Graham N, Gold M, Goldberger B. Prescription opioids and overdose deaths. JAMA 2009; 301:1766-1768.

97. Shields L, Hunsaker J, Corey T, Ward $M$, Stewart D. Methadone toxicity fatalities: A review of medical examiner cased in a large metropolitan area. J Forensic Sci 2007; 52:1389-1395.

98. Kentucky Office of Drug Control Policy. Results of the 2006 Kentucky Incentives for Prevention Survey. The Drug factor 2007; 1:1.

99. Kentucky Justice \& Public Safety Cabinet Office of Drug Control Policy. Opiate addiction increases among youth.
The drug factor 2008; 1:1.

100. U.S. Department of Justice Drug Enforcement Administration. Kentucky State Fact Sheet. 2009. www.usdoj. gov/dea/pubs/state_factsheets/kentucky.html. Accessed June 12, 2009.

101. U.S. Department of Health and Human Services. Summary of findings from the 2000 national household survey on drug abuse. In: Substance Abuse and Mental Health Services Administration 2000.

102. McCarthy W, Zhou Y, Hser Y, Collins C. To smoke or not to smoke: Impact on disability, quality of life, and illicit drug use in baseline polydrug users. J Addict Dis 2002; 21:35-54.

103. Richter K, Ahluwalia H, Mosier M, Nazir N, Ahluwalia J. A population-based study of cigarette smoking among illicit drug users in the United States. Addiction 2002; 97:861-869.

104. Horgan C. Substance abuse: The nation's number one health problem: Key indicators for policy: Update. Robert Wood Johnson Foundation, Princeton, NJ, 2001.

105. Elkholm O, Gronbaek M, Peuckmann V, Sjogren P. Alcohol and smoking behavior in chronic pain patients: The role of opioids. Eur J Pain 2009; 13:606-612.

106. John U, Hanke M, Meyer C, Volzke H, Baumeister S, Alte D. Tobacco smoking in relation to pain in a national general population survey. Prev Med 2006; 43:477-481.

107. Akmal M, Kesani A, Anand B, A S, Wiseman M, Goodship A. Effect of nicotine on spinal disc cells: A cellular mechanism for disc degeneration. Spine. 2004; 29:568-575.

108. Davidson L. Cigarette smoking and its impact on spinal fusions. 2009. Available from: www.spineuniverse.com/ wellness/cigarette-smoking-its-impact-spinal-fusions. Accessed August 29, 2009.

109. Fishbain D. Report on the prevalence of drug/alcohol abuse and dependence in chronic pain patients (CCPs). Sutst Use Misuse 1996; 31:945-946.

110. Hoffman N, Olofsson O, Salen B, Wickstrom L. Prevalence of abuse and dependency in chronic pain patients. Int J Addict 1995; 30:919-927.

111. Reid M, Engles-Horton L, Weber M, Kerns R, Rogers E, O'Connor P. Use of opioid medications for chronic noncancer pain syndromes in primary care. J Gen Intern Med 2002; 17:173-179. 
112. Patterson T, Jeste D. The potential impact of the baby-boom generation on substance abuse among elderly person. Psychiatric Services 1999; 50:11841188.

113. Chabel C, Erjavec M, Jacobson L, Mariano A, Chaney E. Prescription opiate abuse in chronic pain patients: Clinical criteria, incidence, and predictors. Clin J Pain 1997; 13:150-1555.

114. Manchikanti L, Manchikanti KN, Pampati V, Cash KA. Prevalence of side effects of prolonged low or moderate dose opioid therapy with concomitant benzodiazepine and/or antidepressant therapy in chronic non-cancer pain. Pain Physician 2009; 12:259-267.

115. Manchikanti L, Pampati V, Damron KS, Fellows B, Barnhill R, Beyer C. Prevalence of opioid abuse in interventional pain medicine practice settings: A randomized clinical evaluation. Pain Physician 2001; 4:358-365.

116. Saper J, 3rd LA, Hamel R, Lutz T, Branca B, Sims D, Kroll M. Daily scheduled opioids for intractable head pain: Longterm observations of a treatment program. Neurology 2004; 62:1687-1694.

117. Pembrook L. Two screening tests scrutinize urine, identify noncompliant patients. Clin Pain Med August 2005. www.painmedicinenews.com/index.asp?section $i d=82 \&$ show $=$ de pt \& is sue $i d=118 \&$ article_id $=4265$. Accessed June 6, 2009.

118. Pembrook L. High incidence of abnormal urine screens in patients with chronic pain. Pain Med News 2007; 5: http://www.painmedicinenews.com/index.asp?section id $=82 \&$ show $=$ dept $\&$ is sue $i d=288 \&$ article_id $=7912 . \quad$ Accessed March 14, 2010.

119. Workman E, Hubbard J, Felker B. Comorbid psychiatric disorders and predictors of pain management program success in patients with chronic pain. Prim Care Companion J Clin Psychiatry 2002; 4:137-40.

120. Darke S, Wodak A, Hall W, Heather N, Ward J. Prevalence and predictors of psychopathology among opioid users. BrJ Addict 1992; 87:771-776.

121. Reiger D, Locke B, Burke J, et al. Comorbidity of mental disorders with alcohol and other drug abuse. JAMA 1990; 264: 2511-2518.

122. Wasan A, Butler S, Budman S, Fer- mandez K, Jamison R. Psychiatric History and Psychological Adjustment as Risk Factors for Aberrant Drug-related Behavior Among Patients with Chronic Pain. Program and abstracts of the American Academy of Pain 23rd Annual Meeting; 2007. New Orleans, LA, 2007.

123. Tunks E, Crook J, Weir R. Epidemiology of chronic pain with psychological comorbidity: prevalence, risk course, and prognosis. La revue canadienne de psychiatrie 2008; 53:224-234.

124. Hitchcock LS, Ferrell BR, McCaffery $M$. The experience of chronic nonmalignant pain. J Pain Symptom Manage 1994; 9:312-318.

125. Snowdon J, Baume P. A study of suicides of older people in Sydney. Int J Geriatr Psychiatry 2002; 17:261-269.

126. Arharonovich E, Liu X, Nunes E, Hasin D. Suicide attempts in substance abusers: Effects of major depression in relation to substance use disorders. Am J Psychiatry 2002;159:1600-1602.

127. Goldsmith S, Pellmar T, Kleinman A, Bunney W. Reducing suicide: A national imperative. The National Academies Press, Washington, D.C., 2002.

128. Weiss R, Stephens P. Substance abuse and suicide. In: Jacobs D, (ed). Suicide and Clinical Practice. American Psychiatric Press, Washington, D.C., 1992.

129. Kentucky Suicide, Death \& Self-Injury Statistics. Frankfort, Kentucky: Cabinet for Health \& Family Services, Office for Health Policy, Department for Public Health and Department for Mental Health \& Mental Retardation Services; 2005.

130. Shea SC. The practical art of suicide as sessment: A Guide for Mental Health Professionals and Substance Abuse Counselors. John Wiley \& Sons, Inc, Hoboken, NJ, 2002.

131. Buck J, Miller K. Mental health and substance abuse services in Medicaid, 1995. DHHS Pub. No. (SMA) 023713. Rockville, MD: Center for Mental Health Services, Substance Abuse and Mental Health Services Administration, 2002.

132. Synthes. Snythes spine technical guide SynFix-LR system: Instruments and implants for standalone anterior lumbar interbody fusion. www3.hi.is/pub/ hjjr/skrar/036285.pdf

133. Medtronic. Spinal cord stimulation: lindications, safety \& warnings. 2009. http://professional.medtronic.com/interventions/spinal-cord-stimulation/ overview/index.htm. Accessed June 11, 2009.

134. Medtronic. Intrathecal drug delivery: Patient selection. 2009. http://professional.medtronic.com/interventions/ intrathecal-drug-delivery/patient-selection/index.htm. Accessed June 11, 2009.

135. Manchikanti L, Boswell MV, Manchukonda R, Cash KA, Giordano. Influence of prior opioid exposure on diagnostic facet joint nerve blocks. J Opioid Manage 2008; 4:351-360.

136. Manchikanti L, Cash KA, Pampati V, Fellows B. Influence of psychological variables on the diagnosis of facet joint involvement in chronic spinal pain. Pain Physician 2008; 11:145-160.

137. Manchikanti L, Boswell MV, Singh V, Derby R, Fellows B, Falco FJE, Datta S, Smith HS, Hirsch JA. Comprehensive review of neurophysiologic basis and diagnostic interventions in managing chronic spinal pain. Pain Physician 2009; 12:E71-E120.150.

139. Carragee EJ, Alamin TF, Carragee JM. Low-pressure positive discography in subjects asymptomatic of significant low back pain illness. Spine 2006; 31:505-509.

140. Carragee EJ, Tanner CM, Yang B, Brito JL, Truong T. False-positive findings on lumbar discography. Reliability of subjective concordance assessment during provocative disc injection. Spine 1999; 24:2542-2547.

141. Carragee EJ, Tanner CM, Khurana S, Hayward C, Welsh J, Date E, Truong T, Rossi M, Hagle C. The rates of falsepositive lumbar discography in select patients without low back symptoms. Spine 2000; 25:1373-1380; discussion 1381.

142. Carragee EJ, Alamin TF, Miller J, Grafe M. Provocative discography in volunteer subjects with mild persistent low back pain. Spine J 2002; 2:25-34.

143. Manchikanti L, Boswell MV, Datta S, Fellows B, Abdi S, Singh V, Benyamin RM, Falco FJE, Helm S, Hayek S, Smith HS. Comprehensive review of therapeutic interventions in managing chronic spinal pain. Pain Physician 2009: 12:E123E198.

144. Atluri S, Datta S, Falco FJE, Lee M. Systematic review of diagnostic utility and therapeutic effectiveness of thoracic facet joint interventions. Pain Physi- 
cian 2008; 11:611-629.

145. Falco FJE, Erhart S, Wargo BW, Bryce DA, Atluri S, Datta S, Hayek SM. Sys tematic review of diagnostic utility and therapeutic effectiveness of cervical facet joint interventions. Pain Physician 2009; 12:323-344.

146. Datta S, Lee M, Falco FJE, Bryce DA, Hayek SM. Systematic assessment of diagnostic accuracy and therapeutic utility of lumbar facet joint interventions. Pain Physician 2009; 12:437460.

147. Singh V, Manchikanti L, Shah RV, Dunbar EE, Glaser SE. Systematic review of thoracic discography as a diagnostic test for chronic spinal pain. Pain Physician 2008; 11:631-642.

148. Wolfer L, Derby R, Lee JE, Lee SH. Systematic review of lumbar provocation discography in asymptomatic subjects with a meta-analysis of false-positive rates. Pain Physician 2008; 11:513538.

149. Manchikanti L, Dunbar EE, Wargo BW, Shah RV, Derby R, Cohen SP. Systematic review of cervical discography as a diagnostic test for chronic spinal pain. Pain Physician 2009; 12:305-321.

150. Manchikanti L, Glaser S, Wolfer L, Derby $R$, Cohen SP. Systematic review of lumbar discography as a diagnostic test for chronic low back pain. Pain Physician 2009; 12:541-559.

151. Conn A, Buenaventura R, Datta S, Abdi S, Diwan S. Systematic review of caudal epidural injections in the management of chronic low back pain. Pain Physician 2009; 12:109-135.

152. Parr AT, Diwan S, Abdi S. Lumbar interlaminar epidural injections in manag. ing chronic low back and lower extremity pain: A systematic review. Pain Physician 2009; 12:163-188.

153. Benyamin RM, Singh V, Parr AT, Conn A, Diwan S, Abdi S. Systematic review of the effectiveness of cervical epidurals in the management of chronic neck pain. Pain Physician 2009; 12:137-157.

154. Buenaventura RM, Datta S, Abdi S, Smith HS. Systematic review of therapeutic lumbar transforaminal epidural steroid injections. Pain Physician 2009; 12:233-251.

155. Helm S, Hayek S, Benyamin RM, Manchikanti L. Systematic review of the effectiveness of thermal annular procedures in treating discogenic low back pain. Pain Physician 2009; 12:207-232.
156. Smith HS, Chopra P, Patel VB, Frey ME, Rastogi R. Systematic review on the role of sedation in diagnostic spinal interventional techniques. Pain Physician 2009; 12:195-206.

157. Hirsch JA, Singh V, Falco FJE, Benyamin RM, Manchikanti L. Automated percutaneous lumbar discectomy for the contained herniated lumbar disc: A systematic assessment of evidence. Pain Physician 2009; 12:601-620.

158. Singh V, Manchikanti L, Benyamin RM, Helm S, Hirsch JA. Percutaneous lumbar laser disc decompression: A systematic review of current evidence. Pain Physician 2009; 12:573-588.

159. Singh V, Benyamin RM, Datta S, Falco FJE, Helm S, Manchikanti L. Systematic review of percutaneous lumbar mechanical disc decompression utilizing Dekompressor. Pain Physician 2009; 12:589-599.

160. Manchikanti L, Derby R, Benyamin RM, Helm S, Hirsch JA. A systematic review of mechanical lumbar disc decompression with nucleoplasty. Pain Physician 2009; 12:561-572.

161. Manchikanti L, Singh V, Falco FJE, Cash KA, Pampati V. Effectiveness of thoracic medial branch blocks in managing chronic pain: A preliminary report of a randomized, double-blind controlled trial; Clinical trial NCTo0355706. Pain Physician 2008; 11:491-504.

162. Manchikanti L, Singh V, Falco FJ, Cash KA, Fellows B. Cervical medial branch blocks for chronic cervical facet joint pain: A randomized double-blind, controlled trial with one-year follow-up. Spine (Phila Pa 1976) 2008; 33:18131820.

163. Manchikanti L, Singh V, Falco FJ, Cash KA, Pampati V. Lumbar facet joint nerve blocks in managing chronic facet joint pain: One-year follow-up of a randomized, double-blind controlled trial: Clinical Trial NCTo0355914. Pain Physician 2008; 11:121-132.

164. Manchikanti L, Cash KA, McManus CD, Pampati V, Smith HS. Preliminary results of randomized, equivalence trial of fluoroscopic caudal epidural injections in managing chronic low back pain: Part 1. Discogenic pain without disc herniation or radiculitis. Pain Physician 2008; 11:785-800.

165. Manchikanti L, Singh V, Cash KA, Pampati V, Damron KS, Boswell MV. Preliminary results of randomized, equivalence trial of fluoroscopic caudal epi- dural injections in managing chronic low back pain: Part 2. Disc herniation and radiculitis. Pain Physician 2008; 11:801-815.

166. Manchikanti L, Singh V, Cash KA, Pampati V, Datta S. Preliminary results of randomized, equivalence trial of fluoroscopic caudal epidural injections in managing chronic low back pain: Part 3. Post surgery syndrome. Pain Physician 2008; 11:817-831.

167. Manchikanti L, Cash KA, McManus CD, Pampati V, Abdi S. Preliminary results of randomized, equivalence trial of fluoroscopic caudal epidural injections in managing chronic low back pain: Part 4. Spinal stenosis. Pain Physician 2008; 11:833-848.

168. Frey ME, Manchikanti L, Benyamin RM, Schultz DM, Smith HS, Cohen SP. Spinal cord stimulation for patients with failed back surgery syndrome: A systematic review. Pain Physician 2009; 12:379-397.

169. Epter RS, Helm S, Hayek SM, Benyamin RM, Smith HS, Abdi S. Systematic review of percutaneous adhesiolysis and management of chronic low back pain in post lumbar surgery syndrome. Pain Physician 2009; 12:361-378.

170. Patel VB, Manchikanti L, Singh V, Schultz DM, Hayek SM, Smith HS. Systematic review of intrathecal infusion systems for long-term management of chronic non-cancer pain. Pain Physician 2009; 12:345-360.

171. Rupert MP, Lee M, Manchikanti L, Datta S, Cohen SP. Evaluation of sacroiliac joint interventions: A systematic appraisal of the literature. Pain Physician 2009; 12:399-418.

172. Hayek SM, Helm S, Benyamin RM, Singh V, Bryce DA, Smith HS. Effectiveness of spinal endoscopic adhesiolysis in post lumbar surgery syndrome: A systematic review. Pain Physician 2009; 12:419-435.

173. Manchikanti L, Singh V, Helm S, Schultz DM, Datta S, Hirsch J. An introduction to an evidence-based approach to interventional techniques in the management of chronic spinal pain. Pain Physician 2009; 12:E1-E33.

174. Spears V. Congress has national drugmonitoring system on hold. Lexington Herald-Leader April 12, 2009.

175. Gilbert J. Letter to the editors: Ten Cs of chronic non-cancer pain. Am J Pain Manage 2005; 15:45-7.

176. Federation of State Medical Boards. 
2009. www.fsmb.org/. Accessed June 12, 2009.

177. Meadows M. Managing chronic pain. FDA Consumer magazine 2004 June 2004. www.fda.gov/FDAC/features/2004/204_pain.html. Accessed May 21, 2009.

178. Batki S, Kauffman J, Marion I, Parrino M, Woody G. TIP 43: medication-assisted treatment for opioid addiction in opioid treatment programs. SAMH SA/CSAT treatment improvement protocols. Rockville, MD: U.S. Department of Health and Human Services; 2004.

179. U.S. Department of Health and Human Services. Certification of opioid treatment programs: Federal opioid treatment standards. 42 CFR Part 812 (f) (6) 2001.

180. APS opioid guidelines nearing publication. Pain Med News 2008; 6.

181. Wooden J. Prescription drug abuse: What price pain relief? Pain Med News 2009; 7.

182. McMillin G, Urry F. Drug Testing Guide for Chronic Pain Management Services. University of Utah, Salt Lake City, UT, 2007.

183. Louisiana Administrative Code, title 48 , chapter 78, section 7831 .

184. Campbell A. American Academy of Pain Management Pain Program Accreditation: Description and value. www.sbncmd.com/Pain\%2oManagement\%2oPr ogram\%20Accreditation.pdf. Accessed June 25, 2009.

185. Gourlay D, Heit H, Caplan Y. Urine Drug Testing in Clinical practice: Dispelling the Myths and Designing Strategies. zrd ed. PharmaCom Group, Stamford, CT, 2006.

186. Manchikanti L, Singh V, Pampati V, Boswell MF, Benyamin RM, Hirsch JA. Description of documentation in the management of chronic spinal pain. Pain Physician 2009: 12:E199-E224.

187. Manchikanti L, Manchukonda R, Pampati V, Damron KS. Evaluation of abuse of prescription and illicit drugs in chronic pain patients receiving short-acting (hydrocodone) or long-acting (methadone) opioids. Pain Physician 2005; 8:257-261.

188. Berg K, Arnsten J, Sacajiu G, Karasz A. Providers' experiences treating chronic pain among opioid-dependent drug users. J Gen Intern Med 2009; 24:482-8.
189. Cheattle M, Gallagher R. Chronic pain and comorbid mood and substance use disorders: A biopsychosocial treatment approach. Current Psychiatry Reports 2006; 8:371-6.

190. Hojsted J, Sjogren P. Addiction to opioids in chronic pain patients: A literature review. European Journal of Pain 2007; 11:490-518.

191. Mitchell A, Dewey C. Chronic pain in patients with substance abuse disorder: General guidelines and an approach to treatment. Postgrad Med 2008; 120:75-79.

192. Heit H. Guidelines for urine drug monitoring for the pain patient in a clinical practice. Tufts Health Care Institute program on opioid risk management, 2008. www.thci.org/Opioid/juno8docs/Heit\%2oUDM-\%20Tufts\%20June $\% 2026-27 \% 202008 \% 20 \% 20$ Bost on\%2030\%20min..pdf. Accessed June 24, 2009.

193. Gilbert J. Detecting noncompliance: treating pain without fear. [Letter]. Med Econ 2009; 86.

194. Gilbert JW, Wheeler GR, Lingreen RA, Martonffy D, Hatchett J, Gaines R, Stidham S, Sutton T, Westerfield G, McConnell M, Noble S, Carter K. The ten Cs of chronic non-cancer pain: Universal precautions for the chronic noncancer pain patient. Am J Pain Manage 2005; 15:22-32.

195. Manchikanti L, Damron KS, Pampati V, MCManus CD, Weaver SE. Prospective evaluation of patients with increasing opiate needs: Prescription opiate abuse and illicit drug use. Pain Physician 2004; 7:339-344.

196. Gilbert JW, Wheeler GR, Lingreen RA, Scheiner SJ, Upadhyay SP, GyartengDakwa K. Compliance in chronic noncancer pain patients on long-acting opiates, short-acting opiates, or non-opiates. Am J Pain Manage 2006; 16:1217.

197. U.S. Department of Transportation. Procedures for transportation work place drug and alcohol testing programs. 49 CFR Part 40. www.dot.gov/ ost/dapc/NEW_DOCS/part40.html. Accessed June 11, 2009.

198. Marcus D. Managing chronic pain in the primary care setting. 2002. www.aafp. org/afp/20020701/editorials.html.

199. Kozma A. Urine drug screening in ev- eryday practice. Practical Pain Management 2007; (April):18-20.

200. Manchikanti L, Malla Y, Wargo BW, Cash KA, Pampati V, Damron KS, McManus $C D$, Brandon DE. Protocol for accuracy of point of care (POC) or in-office urine drug testing (immunoassay) in chronic pain patients: A prospective analysis of immunoassay and liquid chromatography tandem mass spectometry (LC/ MS/MS). Pain Physician 2010; 13:E1E22.

201. Manchikanti L, Boswell MV, Giordano J. Evidence-based interventional pain management: Principles, problems, potential and applications. Pain Physician 2007; 10:329-356.

202. Boswell MV, Trescot AM, Datta S, Schultz DM, Hansen HC, Abdi S, Sehgal N, Shah RV, Singh V, Benyamin RM, Patel VB, Buenaventura RM, Colson JD, Cordner HJ, Epter RS, Jasper JF, Dunbar EE, Atluri SL, Bowman RC, Deer TR, Swicegood JR, Staats PS, Smith HS, Burton AW, Kloth DS, Giordano J, Manchikanti L. Interventional techniques: Evidencebased practice guidelines in the management of chronic spinal pain. Pain Physician 2007; 10:7-111.

203. Manchikanti L, Giordano J. Physician payment 2008 for interventionalists: Current state of health care policy. Pain Physician 2007; 10:607-626.

204. Manchikanti L, Hirsch JA. Obama health care for all Americans: Practical implications. Pain Physician 2009; 12:289304 .

205. Manchikanti L. Health care reform in the United States: Radical surgery needed now more than ever. Pain Physician 2008; 11:13-42.

206. Manchikanti L, McMahon EB. Physician refer thyself: Is Stark II, Phase III the final voyage? Health Policy Update. Pain Physician 2007; 10:725-741.

207. Manchikanti L, Falco FJE, Boswell MV, Hirsch JA. Facts, fallacies, and politics of comparative effectiveness research: Part 1. Basic considerations. Pain Physician 2010; 13:E23-E54.

208. Manchikanti L, Falco FJE, Boswell MV, Hirsch JA. Facts, fallacies, and politics of comparative effectiveness research: Part 2. Implications for interventional pain management 